\title{
Does pulmonary subspecialty referral from primary care affect the adherence to vaccination recommendations in COPD patients?
}

\author{
Solmaz Ehteshami-Afshar ${ }^{1 *}$, Kristina Crothers ${ }^{2}$, Benjamin Rodwin ${ }^{1,3}$, Brett Bade $^{1,3}$, Cynthia Brandt ${ }^{4,5}$ \\ and Kathleen M. Akgün ${ }^{1,3,4^{*}}$
}

\begin{abstract}
The importance of vaccinations for COPD patients has been previously described. However, there is still a gap between guideline recommendations and the implementation of preventive care delivery for these patients. Specially, the rise of SARS-CoV-2 pandemic has made the significance of vaccination adherence more critical to address. Our study showed that referral to pulmonary clinic is associated with increased odds of receiving influenza (OR $=1.97$, $[95 \% \mathrm{Cl} 1.07,3.65])$ and pneumococcal vaccinations (PCV13 OR $=3.55,[1.47,8.54]$; PPSV23 OR = 4.92, $[1.51,16.02]$ ). These data suggest that partnerships between primary care physicians and pulmonologists can potentially improve the vaccination rates for patients with COPD.
\end{abstract}

Keywords: Chronic obstructive pulmonary disease, Vaccination, Influenza, Pneumococcal vaccine, Referral

\section{Introduction}

Chronic obstructive pulmonary disease (COPD) is one of the most common causes of morbidity and mortality worldwide [1]. Despite the importance of providing guideline-based care, adherence to Global Initiative for Chronic Obstructive Lung Disease (GOLD) recommendations [2] has been sub-optimal, including pharmacologic and non-pharmacologic treatments [3-13]. Preventive treatments with successful vaccinations against lung infections are critical for improving COPD health but adherence can be increased. Vaccination adherence and addressing possible barriers is especially important in the setting of the global respiratory

\footnotetext{
*Correspondence: solmaz.ehteshamiafshar@yale.edu; kathleen.akgun@yale. edu

${ }^{1}$ Internal Medicine, Yale University School of Medicine, New Haven, CT, USA

Full list of author information is available at the end of the article
}

pandemic of SARS-CoV-2. To inform quality improvement targets, we ascertained the adherence to pulmonary infection-related vaccination recommendations in COPD patients, stratified by primary care management alone compared to those with pulmonary subspecialty referral.

\section{Methods}

We performed a retrospective cross-sectional analysis on a random sample of COPD patients receiving primary care $(\mathrm{PC})$ in a single clinical site from January 1 , 2018 to December 31, 2019. Patients first diagnosed with COPD during that timeframe were identified by international classification of disease, tenth revision codes $(\mathrm{ICD} 10=\mathrm{J} 40-44 ; \mathrm{n}=3769)$. We purposefully sampled women $(\mathrm{n}=100)$ and randomly selected 100 men to include in the chart review (5\% sample). Our primary outcomes were vaccination for pneumococcal conjugate (PCV13), pneumococcal polysaccharide (PPSV23) and influenza (3 consecutive 
calendar years 2017-2019), accounting for recommendations in presumably immunocompetent adults with COPD: PCV13 for patients $\geq 65$-years-old; PPSV 23 for patients $\geq 65$-years-old or those with COPD and severely reduced FEV1; influenza for all included COPD patients [2]. We identified vaccination records for PCV13 and PPSV23 (including before the study period), influenza vaccination records (2017-2019), smoking status (current, former, never), age and gender of the patients by detailed chart review of PC and/ or pulmonary text notes from the electronic health record.

Descriptive statistics were used to compare demographic and clinical variables by pulmonary subspecialty evaluation: the student's t-test to compare means for continuous variables and Chi-square test for categorical variables. To assess the association between subspecialty pulmonary evaluation with vaccination adherence, multivariable-adjusted logistic regression was performed and odds ratio (OR) with $95 \%$ confidence interval $(\mathrm{CI})$ were determined. The model was adjusted for age, gender and smoking status. Statistical significance was defined as $\mathrm{p}<0.05$. All statistical analyses were done by IBM SPSS statistics version 25 .

\section{Results}

Among 200 patients (mean age $=70.5 \pm 10.9, \quad 50 \%$ women), 78 patients had pulmonary subspecialty evaluation in the prior 3 years. Patients with pulmonary evaluation were more likely to be current smokers (59\%), had higher pack-year smoking history (48.4 pack-year vs. 37.7 pack-year respectively, $\mathrm{p}=0.01$ ) and were more likely to have had a COPD-related hospitalization in the preceding 12 months $(20.5 \%$ vs. $2.4 \% ; \mathrm{p}<0.001)$ (Table 1). Restricting to patients $\geq 65$ years old, PCV13 and PPSV23 vaccination rates were significantly higher amongst patients referred to pulmonary $(96.6 \%$ vs. $81.6 \%$, $\mathrm{p}=0.009 ; 94.8 \%$ vs. $84.7 \%, \mathrm{p}=0.03$, respectively). Influenza vaccination rates were higher for patients referred for pulmonary evaluation in all years studied compared to those only managed by PC providers: $2017=81 \%$ vs. $63 \%, \mathrm{p}=0.008 ; 2018=80 \%$ vs. $62.5 \%, \mathrm{p}=0.008$; and $2019=70.5 \%$ vs. $52 \%, \mathrm{p}=0.011$, respectively.

In multivariable models adjusting for age, gender and smoking status, pulmonary subspecialty evaluation was independently associated with increased likelihood of vaccination adherence for each of the three vaccines (PCV13 OR $=3.55$, [95\% CI 1.47, 8.54]; PPSV23 $\mathrm{OR}=4.92$, [1.51, 16.02]; influenza $2017 \mathrm{OR}=2.89$, [1.49,

Table 1 Patients demographics and clinical variables

\begin{tabular}{|c|c|c|c|}
\hline & $\begin{array}{l}\text { No pulmonary clinic visit in prior } \\
3 \text { years }(n=122)\end{array}$ & $\begin{array}{l}\text { Pulmonary clinic visit in prior } 3 \text { years } \\
(n=78)\end{array}$ & $p$ value \\
\hline Age in years (mean $\pm S D$ ) & $70.5 \pm 10.8$ & $70.4 \pm 10.9$ & 0.9 \\
\hline Age $\geq 65$-year-old, n(\%) & $82(65.5)$ & $54(69.2)$ & 0.7 \\
\hline Men, n (\%) & $56(45.9)$ & $44(56.4)$ & 0.2 \\
\hline \multicolumn{4}{|l|}{ Smoking status, n (\%) } \\
\hline Never & $6(4.9)$ & $10(12.8)$ & \multirow[t]{3}{*}{0.005} \\
\hline Former & $57(46.7)$ & $20(25.6)$ & \\
\hline Current & $56(45.9)$ & $46(58.9)$ & \\
\hline PFT ever done, n (\%) & $70(57.3)$ & $77(98.7)$ & $<0.001$ \\
\hline Obstructive pattern confirmed on PFT (\%) & $42(60.0)$ & $66(85.7)$ & $<0.001$ \\
\hline FEV1/FVC (mean \pm SD) & $69.4 \pm 11.3$ & $65.1 \pm 14.6$ & 0.07 \\
\hline \multicolumn{4}{|c|}{ Airflow limitation by FEV1 in those with obstructive pattern, n (\%) } \\
\hline GOLD 1 (mild) & $8(19.0)$ & $7(10.6)$ & \multirow[t]{4}{*}{0.02} \\
\hline GOLD2 (moderate) & $28(66.6)$ & $30(45.5)$ & \\
\hline GOLD 3 (severe) & $5(11.9)$ & $24(36.4)$ & \\
\hline GOLD 4 (very severe) & $1(2.4)$ & $5(7.5)$ & \\
\hline PCV13, n (\%) & $71 / 87(81.6)$ & $57 / 59(96.6)$ & 0.009 \\
\hline PPSV23, n (\%) & 100/118 (84.7) & 74/78 (94.8) & 0.03 \\
\hline Influenza vaccination 2017, n (\%) & $77(63.1)$ & $63(80.8)$ & 0.008 \\
\hline Influenza vaccination 2018, n (\%) & $76(62.8)$ & $62(80.5)$ & 0.008 \\
\hline Influenza vaccination 2019, n (\%) & $60(52.2)$ & $53(70.7)$ & 0.01 \\
\hline COPD hospitalization in prior 12 months, n (\%) & $3(2.4)$ & $16(20.5)$ & $<0.001$ \\
\hline Death in 2017-2019, n (\%) & $8(6.5)$ & $5(6.4)$ & 1.0 \\
\hline
\end{tabular}

COPD chronic obstructive pulmonary disease, FEV1 forced expiratory volume in $1 \mathrm{~s}$, FVC forced vital capacity, PFT Pulmonary Function Testing, PCV13 pneumococcal conjugate vaccine, PPSV23 pneumococcal polysaccharide vaccine, SD standard deviation 
5.62]; influenza $2018 \mathrm{OR}=1.79,[0.95,3.39]$; influenza $2019 \mathrm{OR}=1.97,[1.07,3.65])$ (Fig. 1).

\section{Discussion}

In our cohort, we demonstrated persistent gaps between guideline-recommended vaccination in COPD patients and clinical care delivered. While stable COPD is most frequently managed by PC providers [14, 15], pulmonary subspecialty referral was associated with increased odds of pneumococcal and influenza vaccinations in our study. Due to disappointingly low vaccination rate for pneumococcal and influenza, these results illustrate the importance of developing strategies to improve adherence to COPD guidelines for non-pharmacological care in both the PC and pulmonary subspecialty settings.

While pneumococcal and influenza vaccinations have been shown to be effective in reducing COPD exacerbation, hospitalization and mortality of COPD patients [16, 17] vaccination rates, especially for influenza, was suboptimal. Among patients referred to a pulmonary provider, COPD hospitalization in the year before the study period occurred for $20 \%$ in our sample. Hospitalization may mediate the likelihood of vaccination administration but ideally, vaccinations are occurring before COPD exacerbations and hospitalizations. Health illiteracy and lack of awareness regarding the importance and effectiveness of the vaccine is one of the barriers to vaccine uptake, and strategies to address these barriers have been shown to have a positive impact on influenza vaccination rate [18]. This is an area which is ripe for further quality improvement intervention that can address the challenges of campaigns for current vaccination uptake, and also anticipate the potential implications when future vaccines (i.e., SARS-CoV-2) become widely available.

There were several limitations to this study. First, we were unable to assess whether patients were managed by and receiving vaccinations from non-VA pulmonary providers. However, VA Health Factors immunization fields are routinely used by PC providers to enter reported nonVA vaccination status for patients. Second, our sample size limits our ability to detect additional, clinically significant associations and may not reflect practices of $\mathrm{PC}$ and pulmonary subspecialists in more diverse patient populations and/or under different payer models, but can be addressed in the subsequent studies. Third, it is unclear if the vaccinations were not offered or if patients declined the recommendations, although theoretically providers can enter when patients decline immunizations. Finally, we were unable to determine whether vaccinations were provided during pulmonary subspecialty or PC visits. It is possible that $\mathrm{PC}$ providers who refer patients to pulmonary may be more attuned to the COPD guideline care. Thus, partnered management of COPD by PC and pulmonology may translate into improved overall COPD care.

\section{Conclusion}

While there remains ample opportunity to improve vaccination rates in patients with COPD, we showed patients who also received pulmonary subspecialty evaluations were more likely to receive guideline-concordant vaccinations. More studies are needed to better understand the modifiable contributors to poor adherence to

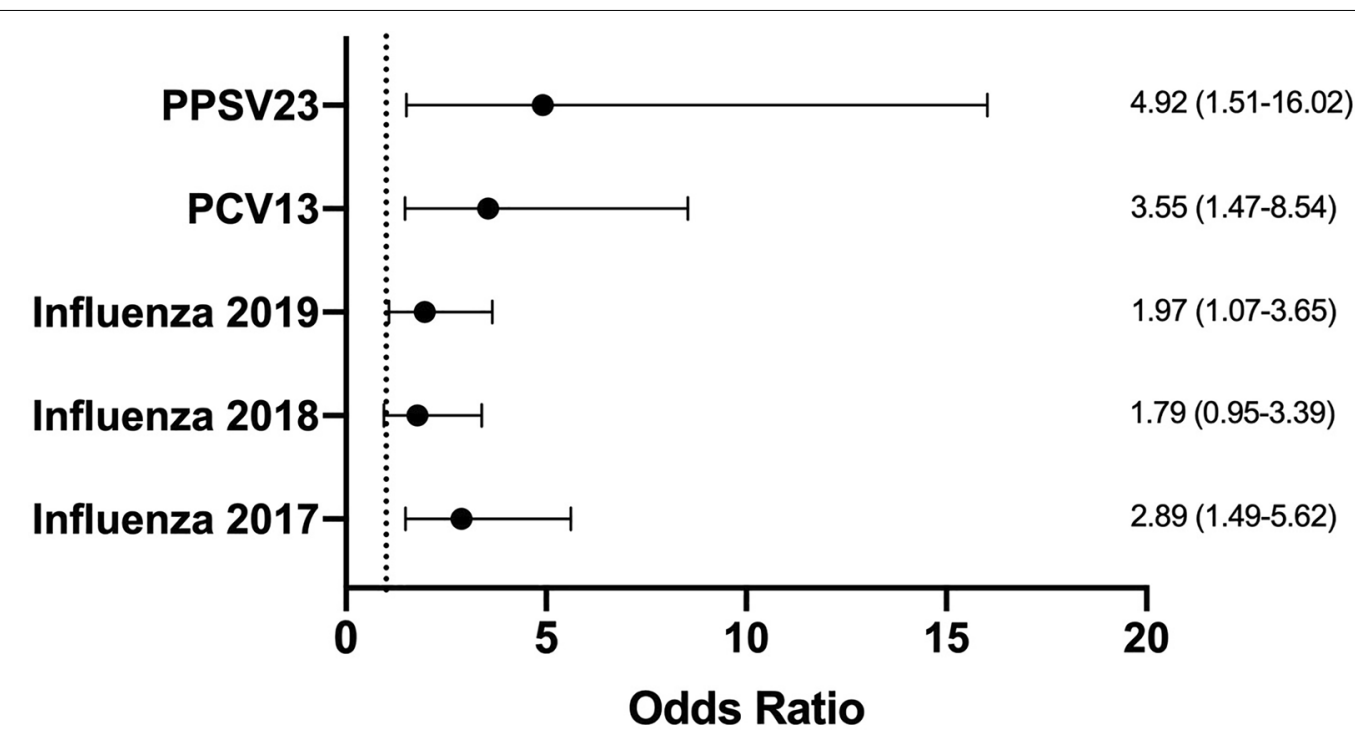

Fig. 1 Odds ratio of pulmonary subspecilaity evalution in the prior 3 years for receiving vaccinations 
vaccinations, especially in $\mathrm{PC}$, and incorporating patient preferences, to improve the COPD management.

\section{Abbreviations}

COPD: Chronic obstructive pulmonary disease; Cl: Confidence interval; GOLD: Global Initiative for Chronic Obstructive Lung Disease; ICD: International classification of disease; OR: Odds ratio; PC: Primary care; PCV13: Pneumococcal conjugate vaccine; PPSV23: Pneumococcal polysaccharide vaccine.

\section{Acknowledgements}

Not applicable.

\section{Authors' contributions}

SEA and KMA formulated the current study idea. SEA and CB performed data extraction and data analyses. SEA wrote the first draft of the manuscript. All authors contributed to interpretation of the findings, critically commented on the manuscript. All authors read and approved the final manuscript.

\section{Funding}

No funding was received.

\section{Availability of data and materials}

The data analyzed in the current study are not publicly available.

\section{Ethics approval and consent to participate}

This work was completed as an operations project at VA Connecticut and VA Greater Los Angeles for the Department of Veterans Affairs through a specific request from VA Women's Health Services within the Office of Patient Care Services. It was also approved by the local Institutional Review Board at VA Connecticut and determined to be operations work.

\section{Consent for publication}

Not applicable.

\section{Competing interests}

The authors declare that they have no competing interests.

\section{Author details}

${ }^{1}$ Internal Medicine, Yale University School of Medicine, New Haven, CT, USA.

${ }^{2}$ Veterans Affairs Puget Sound and University of Washington, Seattle, WA

USA. ${ }^{3}$ Veterans Affairs Connecticut Healthcare System, West Haven, CT, USA.

${ }^{4}$ Veterans Affairs Connecticut Pain Research, Informatics, Multi-Morbidities, and Education Center, West Haven, CT, USA. ${ }^{5}$ Emergency Medicine, Yale School of Medicine, New Haven, CT, USA.

Received: 21 October 2020 Accepted: 27 January 2021

Published online: 12 February 2021

\section{References}

1. Ehteshami-Afshar S, FitzGerald JM, Doyle-Waters MM, Sadatsafavi M. The global economic burden of asthma and chronic obstructive pulmonary disease. Int J Tuberc Lung Dis. 2016;20(1):11-23.

2. Global Initiative for Chronic Obstructive Lung Disease. Global Strategy for the Diagnosis, Management and Prevention of COPD. https://goldcopd. org/. Accessed 16 May 2020
3. Jochmann A, Neubauer F, Miedinger D, Chhajed PN, Schafroth T. General practitioner's adherence to the COPD GOLD guidelines: baseline data of the Swiss COPD Cohort Study. Swiss Med Wkly. 2010;140(3132).https:// doi.org/10.4414/smw.2010.13053.

4. Palmiotti GA, Lacedonia D, Liotino V, Schino P, Satriano F, Di Napoli $\mathrm{PL}$, et al. Adherence to GOLD guidelines in real-life COPD management in the Puglia region of Italy. Int J Chron Obstruct Pulmon Dis. 2018;13:2455-62

5. Grewe FA, Sievi NA, Bradicich M, Roeder M, BrackT, Brutsche MH, et al. Compliance of pharmacotherapy with GOLD guidelines: a longitudinal study in patients with COPD. Int J Chron Obstruct Pulmon Dis. 2020:15:627-35.

6. Ghosh S, Anderson WH, Putcha N, Han MK, Curtis JL, Criner GJ, et al. Alignment of inhaled chronic obstructive pulmonary disease therapies with published strategies. Analysis of the global initiative for chronic obstructive lung disease recommendations in SPIROMICS. Ann Am Thorac Soc. 2019;16(2):200-8.

7. Visentin E, Nieri D, Vagaggini B, Peruzzi E, Paggiaro P. An observation of prescription behaviors and adherence to guidelines in patients with COPD: real world data from October 2012 to September 2014. Curr Med Res Opin. 2016;32(9):1493-502.

8. Johnston K, Grimmer-Somers K. Pulmonary rehabilitation: overwhelming evidence but lost in translation? Physiother Can. 2010;62(4):368-73.

9. Henoch I, Strang S, Löfdahl C-G, Ekberg-Jansson A. Management of COPD, equal treatment across age, gender, and social situation? A register study. Int J Chron Obstruct Pulmon Dis. 2016;11:2681-90.

10. Bereznicki BJ, Walters EH, Walters JA, Peterson GM, Bereznicki LR. Underutilisation of COPD management guidelines in Australian general practice. In Thoracic Society of Australia and New Zealand annual scientific meeting. 2016. Vol. 21, p. 101-185.

11. Kaufmann C, Markun S, Hasler S, Dalla Lana K, Rosemann T, Senn O, et al. Performance measures in the management of chronic obstructive pulmonary disease in primary care-a retrospective analysis. Praxis. 2015;104(17):897-907.

12. Glaab T, Banik N, Rutschmann OT, Wencker M. National survey of guideline-compliant COPD management among pneumologists and primary care physicians. COPD J Chronic Obstr Pulm Dis. 2006;3(3):141-8.

13. Johnston K, Grimmer-Somers K, Young M, Antic R, Frith P. Which chronic obstructive pulmonary disease care recommendations have low implementation and why? A pilot study. BMC Res Notes. 2012;5:652.

14. Johnson M, Rigge L, Culliford D, Josephs L, Thomas M, Wilkinson T. Primary care risk stratification in COPD using routinely collected data: a secondary data analysis. NPJ Prim Care Respir Med. 2019;29:42.

15. Jones R, Price D, Chavannes N, van de Molen T, Thomas M, Tsiligianni l, et al. GOLD COPD categories are not fit for purpose in primary care. Lancet Respir Med. 2013;1(1):e17.

16. Bekkat-Berkani R, Wilkinson T, Buchy P, Dos Santos G, Stefanidis D, Devaster J-M, et al. Seasonal influenza vaccination in patients with COPD: a systematic literature review. BMC Pulm Med. 2017;17(1):79.

17. Froes F, Roche N, Blasi F. Pneumococcal vaccination and chronic respiratory diseases. Int J Chron Obstruct Pulm Dis. 2017;12:3457-68.

18. White S, Chen J, Atchison R. Relationship of preventive health practices and health literacy: a national study. Am J Health Behav. 2008;32(3):227-42.

\section{Publisher's Note}

Springer Nature remains neutral with regard to jurisdictional claims in published maps and institutional affiliations. 